\title{
Art Approach in Inclusive Class to Help Student with Autism
}

\author{
Muchammad Bayu Tejo Sampurno \\ Universitas Negeri Surabaya \\ Surabaya, Indonesia \\ m.bayutejo@gmail.com
}

\author{
Imam Zaini \\ Universitas Negeri Surabaya \\ Surabaya, Indonesia \\ imamzaini@unesa.ac.id
}

\begin{abstract}
This paper tries to answer about the anxiety of the community, especially teachers and parents who are observers of autistic children about the handling of autistic children in Indonesian public schools. Autistic child has a complex communication disorder that makes him live in his own world. It affects the socialization of autistic children with the surrounding environment, including when he went to school. The education system has evolved toward child-friendly with disabilities. The program allows children with disabilities to take classes together with children in general. Communication disorders in autism often occur in the school environment which causes the child difficult to develop his ability. Meanwhile, teachers have less exploration of learning approaches. Art offers flexibility and aspects that are close to children, one of which is fun. This paper uses art-based practiceled research as its approach. The study was a single case study of $R$, a 10-year-old autistic child in Yogyakarta. The results show the art shows its effectiveness as a material delivery approach. In addition, art is also present as a fun therapeutic act for autistic children to improve their thinking, memory, imagination, and communication. The results of autistic children's painting have a high artistic value because there is a qualitative leap in symbol symbols and colors that add to the beauty of the painting.
\end{abstract}

Keywords-autism; inclusive; education; art; painting

\section{INTRODUCTION}

Yogyakarta which is known as the 'city of education', art educators are not always ready to deal with problems related to students in their classes. The current educational system is particularly concerned with the value of school reporting, accreditation, and individual certification beside to what teachers should do as a teacher. Sometimes they forget that current education often deals and rubs against other disciplines and challenging social issues. One is how to deal with autistic children in inclusive classes. Most public schools have therapists who are promoters of counseling tutors. So it is great to think about how many teachers should master their educator's ability to address this problem. Schools in Indonesia have an average of 30 students per class, and some have psychological disorders. Starting from the stress of life like a traumatic experience at home or in the community, minor, moderate, or severe disabilities, communication disorders, and students who just need a little more attention. In fact, the most experienced public art teachers can't handle the diverse needs of all their students within 45-50 minutes or an hour of study. As a result, most educators are not ready to deal with this extraordinary problem with their students. Basically, the teachers have been taught classroom management when they are studying as prospective teachers. However, many of these classes do not discuss in detail what activities can be integrated to address problems in the classroom, from personal to environmental factors.

Art has the flexibility that makes it able to embody with other disciplines. Therefore, an art educator must have an interdisciplinary mind in order to always be able to accommodate art flexibility. What qualifies a person to have the capability of art therapy as an art educator? An art therapist is a professional healthcare provider who uses art as a means of communication and support. The therapist's art projects allow the patient to create art, and during this art-making process the patient can begin to open up to the therapist to begin the therapeutic process. Thus, the artistic process of the students can be seen from the point of view of therapy, creative process, and performance art. Art can lead to better socialization, reduce stress, reduce pain, overcome loss, improve cognitive and motor skills, and enhance a sense of empowerment [1].

An art educator is essentially an artist who shares their knowledge in an academic sense. Art educators demonstrate how to use certain artistic materials, including art movements, history, and lure students in higher-order thinking while creating a work. Throughout the world of education, art educators have felt the flexibility of art, and in fact, some of them have done so even though unconsciously. His artistic flexibility leads to the art of being used as a therapeutic tool for their students.

Currently, there is a gap in the literature that discusses how art teachers should prepare to teach students with a wide range of disabilities since few, if any, studies has been published in the last nineteen years about this [2]. Many teachers feel they lack the knowledge and skills to teach students with emotional and physical disabilities [2]. As a result, many autistic children who enter inclusive classes are not well facilitated. Art educators, therefore, need to find more creative and substantial ways to address the emotional and psychological welfare of students with disabilities in their classes and discover new ways to harness art versatility.

As part of my doctoral studies, I observed students in primary school in Yogyakarta. Some of these students were diagnosed with autism and have a communication problem. 
Through my own personal experience of working as people who love the world of child art education with all its dynamics, I observed children as young as ten years old who are treated using chemical drugs that have many side effects. As an art educator, I also noticed during my student teaching that many students in the classes I worked with struggled to cope with issues such as emotional and physical abuse, suicide, bullying, depression, and many other difficult experiences including disabilities such as sensory defects to autism. The lack of training on these issues and the lack of special education aides are also very concerning and lead me to think about ways to incorporate more meaningful instructional strategies I could eventually use in my classroom. The strategies referenced in this paper are based on my own personal observations of what other teachers and art therapists have used as a way to deal with some of these issues and thus became a way for me to think about ways to improve my own teaching for future use. In this paper, I will discuss the artistic approach I did to the autistic child in the inclusion class in Yogyakarta. I then discuss the results of the work produced and the values that are in it from the approach I use as an educator in the classroom.

\section{RESEARCH METHODS}

This research method is ethnographic case study. The study was conducted on R (10 years), an autistic child who was in Yogyakarta Indonesia. Ethnography is done for 6 months. The data presented in this paper is the data of the research sample, by displaying one $\mathrm{R}$. painting. The painting was analyzed using in-depth observation methods and supported by the interaction of researchers with $\mathrm{R}$ during the painting process.

\section{RELATION OF AUTISM IN ART}

\section{A. Autism}

Autism is a neurological disorder characterized by qualitative impairment in social interaction and communication as well as the presence of restricted, repetitive, and stereotyped patterns of behaviors, interests, and activities [3]. Complex communication disorder causes autistic children to live in their own world. Furthermore, children with autism often exhibit behaviors in which they can not make good eye contacts, such as ignoring their surroundings and lack of empathy. This causes autistic children are often isolated and not accepted by the environment. Though an autistic child will be able to communicate if the interlocutor understands his characteristics. I had the experience of meeting an autistic child, where exactly he could communicate fluently with me rather than with his own family. At that time his family was astonished and asked "what happened, it's miracle", then I told him what I knew. My advice is well received by the child's family and I believe the child's communication with his family is improving. In addition, please note that there are many ways to communicate like we are communicating with various media. Autistic child communication media not only through verbal but also nonverbal. Movement, gaze, art, and painting is an effective communication medium for autistic children. This is because by doing non-verbal communication, children with autism intermedia communications that also improve their multisensory ability. In other words, in addition to communicating, motor activities, of course, it is an excellent therapeutic activity for children with autism.

\section{B. Art Therapy and Processes: When Art is Really Healthy}

Art therapy is a combination of an in-depth understanding of art as well as an equal understanding of psychology and health. Art therapy is to be a procedure designed to assist favorable personality changes or living that will outlast the session itself [4]. The goal of someone who does art therapy is to help in understanding, also help a child grow in change. My goal as an educator as well as an art therapist is that students have a high sensitivity to the surrounding phenomena delivered through art. This will also improve the communication of children with autism. The artwork will be applied to various applied media and will be exhibited so as to increase the degree of autistic children in the eyes of the wider community so as to enhance their confidence, and express ideas that may be difficult for them to communicate through words.

As a psychotherapist, Rubin was drawn to what could not be seen in children's minds. Art gave the chance to look for the forbidden and beyond. Art was like private feelings made into public form [4]. Just as many autistic children are said to live in their own world, art is one of their ways to expand their communication. The autistic thought of a 'special' autistic child, will be 'general' by art. Personal expressions will be presented with symbols that many people can enjoy, and are reviewed by some experts using appropriate approaches. This will make the child with autism become like a normal person who is able to communicate. Furthermore, in the process of painting children with autism will be given a stimulus by the therapist to communicate. Telling live what he delivered through painting. The occurrence of two-way communication is very important because, in addition to communicating, the brain will record many new vocabularies that are very useful for children with autism in communicating verbally in the future.

Rubin examines the history of art therapy and several pioneers' views of helping children through the arts. In the early developments of mental health, educators found the benefits of a freer artistic expression in the school system. During the 1950s educators were convinced that the arts and other creative experiences were vital to children's education and overall development [4].

\section{Visual Art and Autism}

The main function of artistic expression for autistic children is to record their own visual thoughts, not to communicate the visual thoughts to others [5]. Often the visual thoughts represented in the symbolization of form and color in his paintings are obsessions, preoccupations, derived from experiences experienced. $\mathrm{R}$ has long made illustrative paintings with media markers, pens, or pencils that visually represent his life experience. Thus, I see that the painting made is for his own satisfaction, not to communicate the experience, but to record it. Some of the paintings he made there are even 
qualitative leaps that are far away in the future that allow us to glimpse the world to come.

Art educators recognize that visual art is a form of communication [6]. There are some experts who refer to children's artwork with autism as a form of communication [7]. Art educator Dr. Julia Kellman argues that children with autism are able to "develop visual vocabulary that seems to create and express meaning for the child" [8].

Dr. Temple Grandin is a professor at Colorado State University, writes that many individuals with autism are visual thinkers. He stated in his book Thinking in Pictures, "I think in pictures, words like a second language to me" [9]. He argues that after questioning how others access information from their memories [9], he becomes aware that his visualization skills go far beyond most 'normal' individuals. He explains that adults with autism who are able to talk about their thought processes suggest that most of them 'think in visual images' [9]. The processing of information through memory usually appears in the autistic child's imagination in appropriate and specific chronological order, so the visualized image is always specific. This is supported by Grandin's argument that the mind of an autistic child can be likened to a 'video library', which contains visual images for all that has been heard, read, or seen.

\section{HANDLING INCLUSIVE CLASS WITH ART}

While at the undergraduate level, precisely in the department of fine art education, I was given teaching supplies in the form of mental and classroom management. From my learning experience at undergraduate level, it provides my experience and understanding when managing the class. This allows me to explore creative ideas in teaching innovations in the classroom where I work.

\section{A. Three Simple First Step when Entering the Classroom}

The first step taken to determine the appropriate method of education for children with autism in the class of inclusion is by way of observation. Observation has an important role, because with detailed and specific observations, we can see how the habits of children with autism in the classroom. The results of these observations will be used as an early instrument of designing educational materials to be provided. The second step is to do a 'simple game', that is by sharing art media freely to the students. Seeing how they treat the art media will give educators an idea of the focus of painting they love. On the basis of pleasure, will facilitate the therapist's efforts in doing therapeutic process wrapped in art learning materials. It will also provide an opportunity for the therapist to better prepare for the treatment to be performed. The third step is an interview wrapped in a documentary study of student learning outcomes of autism. Usually I will ask for help to the teacher or the manager of the class even the principal to be allowed to see and discuss the achievement of student learning outcomes autism. In 2010 I worked at a special school for autism in Yogyakarta. I did the steps I mentioned above, where I will focus on the third step. In that step I see the learning result of one of the students is very dominant in the mathematics lesson. Then I tried to do a simple test of the students' math skills. The result is very satisfying. Then I gave him paper and markers, and he was very good at drawing geometric shapes. But strangely he can't draw organic shapes at all. From my observations, documentation studies and interviews, I can understand the artistic style of arts possessed by the students.

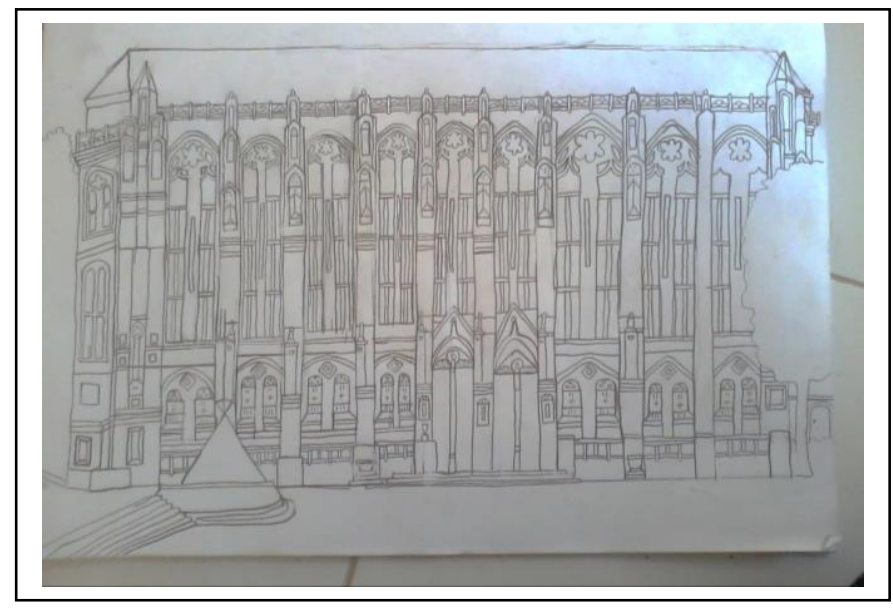

Fig. 1. Library painting created by one of the autistic children with high mathematical ability

It was proven when he gave me the task to draw a library that I took pictures from the internet. At that time he drew it from left to right. When engrossed in drawing, his friend interfered and he did not like it. So he had tantrums. He ran around the school complex several times and finally returned to his seat. He continued drawing from right to left. It was amazing to see his painting in the middle without looking strange. He does not use eraser or ruler, but still capable of precision in drawing. The experience makes ongoing research on art and mathematical relationships for the students, and opens the opportunity to become one of the therapeutic media.

\section{B. Developing Course Materials Centered on Creativity}

Art is full of creativity. If examined in detail, actually all things in life requires creativity. Also with non-art teaching materials in schools. Creativity is a method for solving problems in different ways. Using an art approach to help autistic children understand educational materials in inclusion classes, it will challenge teachers to develop their delivery methods to make them more unique, creative, and fun.

The main goal of the art approach as art therapy in schools is to help students through academic difficulties. Therefore, teachers occupy an important position in the achievement of students achieving the achievement of educational materials in schools. But the soft-skill of empathy is of paramount importance compared to the learning achievements tested by examination. The art approach in education seeks to improve the ability of ego control, emotional maturity, and controlled behavior. The emotions in the child are positively channeled through the art, through the creative process, and produce artwork that has the value of beauty that can be enjoyed by others. There is a change in attitudes and attitudes and emotional development to a better, controlled emotional 
experience when they participate in creative and productive acts of art making [4].

When this research began, my main research question was to investigate whether the principles of art in combination with therapy (health), education, and developmental principles with therapy can help children with autism through their creative exploration, increase spontaneity and promote artistic autonomy. Based on my experience as an art therapist, I hope that I will be able to dilute the theoretical orientation of artistic pleasure into a technique that can provide an alternative therapeutic action of autistic children with the help of art.

When I started my work in class R, I felt an immediate desire to try to use the art approach. $\mathrm{R}$ has so many characteristics that are slightly different from the autistic child in general. Hunting my identification, through observation, documentation studies, and early-stage testing to determine the right handling for $\mathrm{R}, \mathrm{R}$ is a high functioning autism that is more likely to be in the visual learner. Therefore I am convinced that my approach will succeed on R. Considering my best interests, I discuss my approach with ABA therapists and parents of R, and find that no one has ever approached art in classroom teaching in inclusion. We discuss how I will try to use an art approach that is integrated with ABA principles, as a way to expand repertoire, build skills, work with behavior and strive to increase confidence and autonomy. Eventually I determined the scope of work in which I would try to follow the R pattern, while indirectly teaching and developing the scheme through the use of the art approach. That I did because it turns out R has the privilege, where I have a lot to learn from him. In short we learn from each other. Therefore, I decided to go hand in hand with R. Not in the front to pull it, or be behind to push it. We go hand in hand and negotiate each other. It makes $\mathrm{R}$ feel comfortable because he feels I understand and understand him.

With R, I saw a child who seemed so open to learning and artistic exploration. The therapeutic relationship with $\mathrm{R}$ develops very rapidly. She was always able to convey what she thought through painting and telling me stories. He is a child who is genuinely interested in art and the media of art and I see his potential in a short time. This is one of the main reasons why I chose to try to use the art approach to his education.

With the permission of his family, I began an art approach in his education by observing his skill level, while observing his behavior in terms of verbalizations. I immediately witnessed R's strong desire for his image. It shows that his confidence has improved. His motor skills and communication improved, and his autistic behavior diminished. During our 'therapy' session, the persistence of $\mathrm{R}$ was excellent, where at the end of our therapy, I actually had hundreds of paintings with beautiful symbols with impressive details.

When the material about 'My Family', I joined the classroom with $\mathrm{R}$. When the teacher gave the task to make a story about the family. I offer R blank paper with markers of different colors. I told R "what are you doing at home?", "How is your house, your mother and father?", "What usually happens in your house?", and other stimulus questions about family. When I asked the question, R just kept quiet and like to think a thing. And not long after, even when I was asking a stimulus question, $\mathrm{R}$ had started painting.

\section{Artistic VAlue of Autism Paintings}

In this section I will give you a painting made by $\mathrm{R}$ in 2017 . This painting is painted with a media marker on a $30 \times 40 \mathrm{~cm}$ canvas.

\section{A. The Artwork Description}

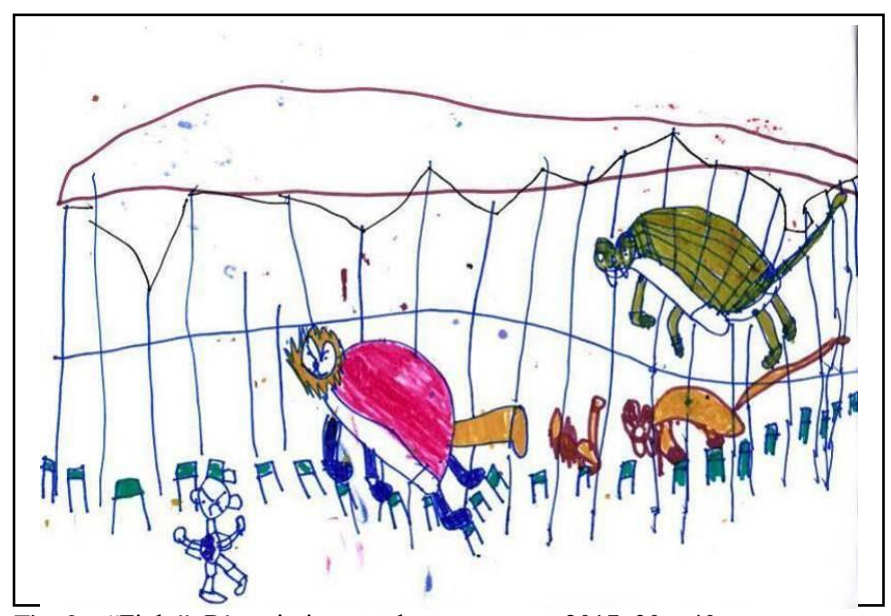

Fig. 2. "Fight", R's painting, marker on canvas, 2017, 30 x $40 \mathrm{~cm}$.

The work entitled "Fight", describes the atmosphere of gladiator-style battles in the Colosseum because in addition to symbols drawing Colosseum as the arena of fighting the gladiators with animals, it also appears the symbol of the image of the gladiator and animals that become opponents in the fight. In the painting process, $\mathrm{R}$ looks active. Sometimes $\mathrm{R}$ asks me to take action, invite to play the war, then continue painting again. $\mathrm{R}$ painted while telling stories, shouting the animal sounds was painted, and imitating the style as involved in the fight, like joining and embodied into the story.

The object shown in the artwork is a figure of a human who in this painting acts as Gladiator, animals, building Colosseum, and stands audience. The first object is human, the arrangement of head, body, hands and feet has been seen in the human figure that made $\mathrm{R}$ in the artwork above. The human figure wearing armor like Gladiator. The color used in this figure is blue. The second object in the middle section, there appears the animal form identified as a lion. The lion's shape is emblazoned with accessories like a red robe that is mounted on the lion's body. The colors used are red, white, light brown, and blue. The third object, the object that lies beside the right of the second object. The third object looks the shape of a lion boy, light brown. The fourth and fifth objects are on the right, visible form of tiger. Then there is the object shaped audiences chairs at the bottom. The sixth object is seen form the Coliseum building that became the battleground. The above painting is included in a non-haptic or realistic type of painting, since the form is already identifiable, and the forms are arranged according to the story.

At the time of painting, $\mathrm{R}$ looks active. $\mathrm{R}$ made the painting as a media to play herself. In this playing activity, imagination, 
thoughts and feelings move to create the game. $\mathrm{R}$ also makes painting as a medium to express his heart of ideas, as well as revealing the events that have experienced and seen by him. R's behavior when painting was seen in R's painting of the fight. The spoiled nature that $\mathrm{R}$ shows in the painting process is also evident in R's paintings on the contents and intent of the painting story entitled "Fight".

\section{B. Key Point of R Painting "Fight"}

1) The concept of shape and time as qualitative leaps: visualize a human figure who in this painting is identified as a gladiator who is a self-portrayal, preparing for the animals in the fight at the Colosseum. This painting penetrates the concept of space and time, where R's painting brings us back to the time of the Roman empire.

2) The transparency that appears in the painting: the gladiatorial battle with animals occurring within the colosseum arena is revealed by $\mathrm{R}$. Shows the transparency that appears in the painting.

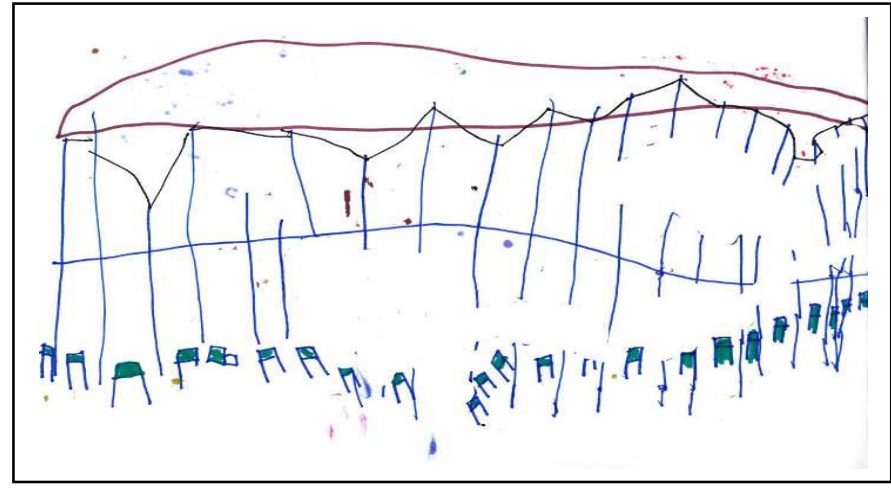

Fig. 3. The transparency concept of Colosseum

3) Gladiator and anomaly object: if we imagine, chickens do not belong to the animals that are fought in the show at the Colosseum, but here $\mathrm{R}$ adds chicken to join the fight. R's father are chickens farmer. R's affection for his father is huge, so is R's father, but R feels his father's attention is diminished because of the attention his father splits on his chickens. $\mathrm{R}$ wants to fight with his father's cock, because if chicken defeated, $\mathrm{R}$ gets his father's attention. That is behind the making of chicken in this painting. Gladiator in R's painting is played by himself. It is as an egocentric form possessed by $\mathrm{R}$. He wants to fight the animals, especially the chickens. $\mathrm{R}$ does not like his father to raise chickens, as $\mathrm{R}$ often feels that his father is more concerned with chicken than he is. Though it's just R's feelings, because in fact R's father has never subordinated R, but there's still a desire from $\mathrm{R}$ to fight the chicken meant if his chicken loses, then $\mathrm{R}$ will get $100 \%$ attention from his father.

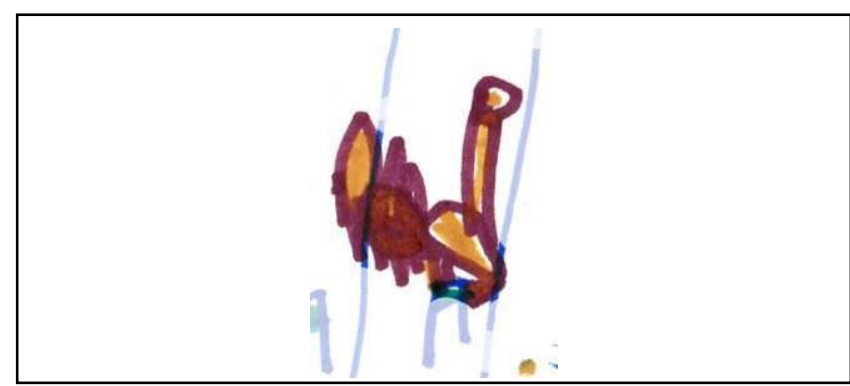

Fig. 4. Chicken as anomaly object in R painting

4) Lions as an environmental representation of $R$ : the lion is one of R's fight opponents in his paintings. The lion was given a costume by $\mathrm{R}$ in a red robe covering her body. The expression of the lion seemed to underestimate the $\mathrm{R}$ ablitiy. It is a representation of the environment, where $R$ is often underestimated by those around him. The lion in R's painting is portrayed as leaping for $\mathrm{R}$, visualized in the shape of a sleek leg that resembles the jumping motion and the distance between the lion's legs and the bottom line of the painting.

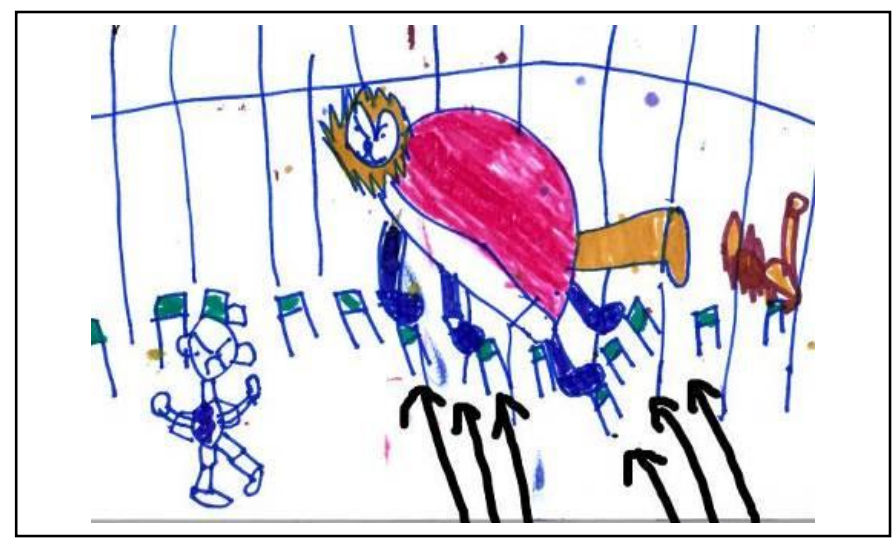

Fig. 5. Direction of the lion's leap that is visualized through the symbol on the foot

5) Tiger as clue painting: there are two tigers in this painting, namely the young tiger and the old tiger are both identified from body color and face character. The young tiger uses orange, and the character of a face that marks the young age. The old tiger used green because he was imported from the past. Green color is defined as a tiger whose body is full of moss, but he entered into the time machine and arrived at the Colosseum.

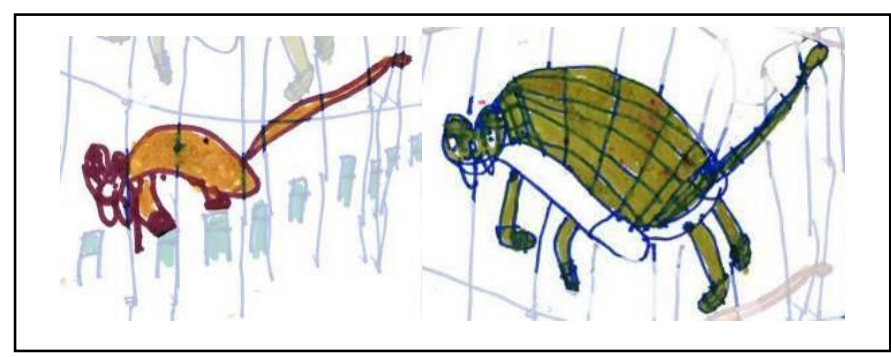

Fig. 6. Tigers that become clue on painting through face characters and color symbols 
All the analysis I know because it really follows the creative process undertaken by $\mathrm{R}$. He smoothly tells what he felt and experienced. His painting was made spontaneously and flowed by. He did not think about what people would perceive to his paintings. He does not care about right-wrong, and what he does is really art.

\section{REFERENCES}

[1] https://www.arttherapy.org/AutismToolkit/autismtoolkit.pdf

[2] M. B. Coleman, E. S. Cramer, Y. Park, and S. M. Bell, "Art Educators' Use of Adaptations, Assistive Technology, and Special Education Supports for Students with Physical, Visual, Severe and Multiple Disabilities," Journal of Developmental and Physical Disabilities., vo. 27 , no. 5, pp. 637-660, 2015
[3] American Psychiatric Association, Diagnostic and Statistical Manual of Mental Disorders (4th edn., text revision). Washington, DC: American Psychiatric Association, 2000.

[4] J. A. Rubin, Child art therapy: 25th anniversary edition. Hoboken, NJ: John Wiley, 2005.

[5] C. C. Park, Exiting Nirvana: A Daughters Life with Autism. Boston: Back Bay Books, 2001.

[6] A. D. Efland, Art and Cognition: Integrating The Visual Arts in The Curriculum. New York: Teachers College Press, 2002.

[7] K. Evans and J. Dubowski, Art Therapy With Children on The Autistic Spectrum: Beyond Words. London/Philadelphia: Jessica Kingsley Publishers, 2001.

[8] J. Kellman, "Drawing with Peter: Autobiography, Narrative, and The Art of a Child with Autism," Studies in Art Education., vol. 40 no. 3, pp.258-274, 1999.

[9] T. Grandin, Thinking in Pictures: And Other Reports From My Life with Autism. New York: Vintage, 1995. 